\title{
The Key Party in the Catalan Government*
}

\author{
Enriqueta Aragonès ${ }^{\dagger}$ \\ Institut d'Anàlisi Econòmica, CSIC
}

February 2007

\begin{abstract}
This paper analyzes the different compositions of the catalan governing coalitions during the current democratic period, and offers some predictions about the coalitions that can be expected in the future. During this period, in catalan politics, there have been two main political issues over which the different parties have taken positions: rightist versus leftist with respect to economic policy, and sovereign versus centralist with respect to the power distribution within the state. I find that for any allocation of parliament seats there is a key party: a party that has a clear advantage in terms of being able to decide the composition of the governing coalition. I show the features that allow a party to become the key party and those that affect the size of the advantage of the key party.
\end{abstract}

\section{Introduction}

During the current spanish democratic period, in catalan politics, there have been two main political issues over which the different parties have taken

*Thanks are due to Andreu Ferré, Marta Guspí, Larry Kranich, and Angel Solano for helpful comments. The author acknowledges financial support from the Spanish Ministry of Science and Technology, grant number SEC2003-01961 and CREA-Barcelona Economics. This paper is part of the Polarization and Conflict Project CIT-2-CT-2004-506084 funded by the European Commission-DG Research Sixth Framework Programme. This article reflects only the author's views and the Community is not liable for any use that may be made of the information contained therein.

${ }^{\dagger}$ Institut d'Anàlisi Econòmica, CSIC. Campus UAB, 08193 Bellaterra (Spain). enriqueta.aragones@uab.cat 
positions: rightist versus leftist with respect to economic policy, and sovereign versus centralist with respect to the power distribution within the state. For a description of the catalan nationalist movements see Guibernau (1997) and Weiss (2002).

Given the relevance of these two issues, catalan parties have defined their ideologies taking positions over them. Even though at the first elections of the period (1980) there were six parties competing, over the years the parliament seats have been allocated to mainly four parties, with different ideal positions in the two dimensional policy space: CIU nationalist and rightist, ERC nationalist and leftist, PPC centralist and rightist, and PSC centralist and leftist. Table 1 contains the results of all elections for the catalan parliament held between 1980 and 2006.

In order to analyze formally the formation of a governing coalition in this environment I will use the model described in Aragones (2007) specially suited for four parties competing in a two dimensional policy space. Throughout this paper it should be understood that a governing coalition refers to the coalition of parties that offers support to the government, and it does not refer necessarily to the allocation of cabinet ministers. Laver and Schofield (1990) offer a detailed description of the roles of executive and legislative coalitions in european democracies.

After almost forty years of dictatorship in 1977 the first democratic elections were held in Spain. In 1978 took place a referendum on the current spanish Constitution. It allowed for a new regime that included a system of Autonomous Communities. In 1979 took place a referendum on the Catalan Statute and in 1980 the first Catalan parliament was elected. Guibernau (1997) offers a detailed description of the spanish transition to the 'state of autonomies'. Colomer (1998) describes the decentralization process of Spain and compares it to different federal and regional organizations.

With respect to the catalan governing coalitions formed during the democratic period we have that in 1980 the governing coalition that formed included CIU, ERC, and UCD. This election can also be thought of as a transition election, since political parties were being formed and legalized after forty years of dictatorship.

In the first three elections after 1980, CIU obtained an absolute majority of seats in the parliament. Obviously in those cases (the legislatures starting at 1984, 1988, and 1992) the government was formed by party CIU alone; there was no need to bargain over policy, and the policy implemented was determined by CIU alone. In the next two elections, corresponding to the 
legislatures starting at 1995 and 1999, the governing coalition that formed was CIU with PPC. Finally, the governing coalitions formed in 2003 and 2006, included PSC, IC and ERC.

Formal Model:

Aragones (2007) describes a model of government formation in a two dimensional policy space and shows how a given electoral result leads to a given government analyzing a model of government formation with a two dimensional policy space. The predictions are described by a coalition of parties supported by a majority of votes, and a policy supported by the parties in the coalition. A characterization of all stable government configurations in terms of coalitions and policies is provided.

The solution concept used is based on stable governing coalitions. The concept of the core, borrowed from cooperative game theory (see, for instance, Moulin (1988) or Myerson (1990)) is used as a measure of stability. This assumption is particularly relevant when I consider the formation of the coalition that sustains an executive in office on the basis of a confidence vote. The members of this coalition consume all the benefits of office-holding, and have the control of all policy outputs. There is no binding agreement in this coalition: a non-confidence motion may be proposed at any time. In the legislative bargaining model that I present the non-empty core conditions described by Plott (1967) are satisfied for a large range of parameter values. These conditions guarantee the formation of a stable governing coalition.

It is assumed that parties care mostly about holding office, and only instrumentally about policy, that is, they are concerned about their policy choice because by compromising their ideology today, they might jeopardize their vote support in future elections and thus their future expected payoff in terms of their probability of holding office in the future. A party's current value of holding office is represented with an exogenous positive constant. The value of holding office can be also thought of as an individual rationality constraint for the party: it represents the maximal amount of utility that it is willing to give up in terms of policy. For example, a party that attaches a large value to holding office might be willing to commit to policies far away from its ideal point in order to guarantee becoming a member of the winning coalition.

I assume complete party discipline, that is, I assume that all members of a party have the same preferences. Therefore, I define the preferences and actions of a given party as representing the preferences and actions of all its members. I assume that different parties have different ideal points in 
a two dimensional policy space. I consider four parties whose ideal points are represented by the vertices of the unit square. If different parties share the same ideological position over the two relevant dimensions I assume that they form a natural coalition that acts as a unique strategic agent when bargaining to form a government. However, in most cases I find a unique party for each position. Thus, I can classify the parties into four ideological groups (see table 2). The groups identified as CIU, ERC and PPC represent the corresponding party.

The case of PPC needs a justification: I have identified it with UCD, CDS and AP before 1992, when PPC was created. The reason is that it can be thought that over time these parties have only changed their name but not their ideology. I have also included in the ideological group 'rightist and centralist' denoted by PPC the seats obtained by the party "Ciutadans" during the last election. According to his ideology, this party could be included in either PSC or PPC, and in either case my results would not be affected. I have chosen to add this small party to the other smallest party, PPC, in order to make my results stronger.

Similarly, the creation of IC in 1988 can be thought of as a replacement of a former leftist party, PSUC. The fourth group identified as PSC+IC represents two different socialist parties. Since 1988, PSC obtains one of the largest share of the votes and IC obtains one of the smallest. In addition they share a leftist ideology and none of them has shown a clear nationalist one. Thus, it does not seem a strong assumption to consider them as a natural coalition.

I assume that a governing coalition can only be formed with the support of a majority of the votes of the parliament, that is, it must be a winning coalition according to majority rule. And I also assume that only governing coalitions can decide on the policy to be implemented. In case a single party has a majority, it can implement its ideal point on both issues. my interest focuses on those cases in which no party has a majority. In my formal analysis I will identify a minority government with the coalition that has offered its support to allow the formation of the government, even in those cases in which only one party enters the cabinet.

Using this model I find that in the catalan political environment for any allocation of parliament seats only two scenarios are possible: either there is a party that is a member of almost all equilibrium coalitions (dominant party scenario) or there is a party that is never a member of an equilibrium coalition (dominated party scenario). I find that in each one of these scenarios 
there is a key party: a party that has a clear advantage in terms of being able to decide the composition of the governing coalition. I characterize the key party for each possible scenario and I show that it is sufficient that the key party has intense preferences over one of the issues to guarantee the formation of a stable government coalition. In addition, I show the features that allow a party to become the key party and those that affect the size of the advantage of the key party. Using these results, I analyze the different governments that have formed in Catalonia between 1980 and 2003, and I offer some predictions about the different government configurations that can be expected in the future.

The rest of the paper is organized as follows: the next section describes the formal model. Section 3 characterizes the coalitions that may form in equilibrium and the policies that can be supported in equilibrium by such coalitions. Section 4 contains the discussion of the results and some possible extensions of the formal model. Section 5 describes the implications of the results over past and future governments of Catalonia. Finally section 6 presents some strategic implications for the catalan parties.

\section{The Model}

I analyze an application of the model described in Aragones (2007) that fits the specific features of the catalan political environment. I consider a two-dimensional policy space represented by $\Re^{2}$. I denote a policy by $(e, s) \in \Re^{2}$ and I interpret $e$ and $s$ as a pair of policy positions on the two issues: economic policy and nationalism, denoted respectively by $E$ and $S$. Parties are characterized by their ideal points in the policy space. Let $\left(e_{i}, s_{i}\right) \in \Re^{2}$ denote the ideal point of party $i$. I assume that there are four parties denoted PSC+IC, ERC, CIU, and PPC. I normalize their ideal points in such a way that they can be represented by $(0,0),(0,1),(1,1)$, and $(1,0)$ respectively. That is, on the economic issue 0 represents a leftist position and 1 represents a rightist position, whereas on the nationalist issue 0 represents a centralist position and 1 represents a nationalist position. Assuming that the ideal points of the parties are located at the edges of the unit square simplifies greatly the analysis. A discussion about how it could be relaxed without affecting qualitatively the results can be found in Aragones (2007).

I assume that an election has already taken place, and the proportions of parliament seats that each party has obtained are given by $v_{P S C+I C}, v_{E R C}, v_{C I U}$, 
and $v_{P P C}$. Thus, I have that $v_{P S C+I C}+v_{E R C}+v_{C I U}+v_{P P C}=1$ and $0 \leq v_{i} \leq 1$ for all $i \in\{P S C+I C, E R C, C I U, P P C\}$.

I will restrict my analysis to the cases in which $v_{i}<\frac{1}{2}$ for all $i$. The case in which there is a party $i$ such that $v_{i}>\frac{1}{2}$ leads to a trivial analysis: this party alone will form the government and the implemented policy will coincide with its ideal point. The case in which there is a party $i$ such that $v_{i}=\frac{1}{2}$ is not considered either, because it is not possible in the catalan parliament since the number of seats is odd (135 seats).

I assume that parties are mainly concerned about holding office, that is, they derive utility from being members of the governing coalition. I also assume that the governing coalition has to implement a policy. Even though this model does not consider any strategic role played by the voter, I assume that at each election voters decide their vote by evaluating parties according to the policies chosen while in office. Since voters care about the policy implemented I assume that they consider the members of the governing coalition responsible of the policy choice made. Therefore, even though I assume that parties are mainly concerned about holding office, I have that, indirectly, parties that are members of the governing coalition care about the policy implemented, since it may affect their vote support in future elections. I assume that the payoffs of parties that are not members of the governing coalition are not affected by the policy choice of the government, since voters do not hold responsible of the policy choice those parties that are not in the governing coalition. I normalize the utility of a party that is not a member of the governing coalition to zero, and I represent the utility that party $i$ obtains if it becomes a member of the governing coalition when the implemented policy is $(e, s) \in \Re^{2}$ by $U_{i}(e, s)$. Therefore, I can write the payoff function of party $i$ as follows:

$$
V_{i}(C,(e, s))=\left\{\begin{array}{cl}
0 & \text { if } \quad i \notin C \\
U_{i}(e, s) & \text { if } \quad i \in C
\end{array}\right.
$$

where $C$ denotes the governing coalition, $(e, s)$ represents the implemented policy and $U_{i}(e, s)$ is given by:

$$
U_{i}(e, s)=k_{i}-\epsilon_{i}\left(e-e_{i}\right)^{2}-\sigma_{i}\left(s-s_{i}\right)^{2} \quad \text { with } \epsilon_{i}, \sigma_{i}>0 \text { and } \epsilon_{i}+\sigma_{i}=1 .
$$

where $k_{i} \in \Re^{+}$represents the utility that a party derives from being a member of the governing coalition. According to this utility function, parties' 
preferences over policies are single peaked and convex but not necessarily symmetric. The parameters $\epsilon_{i}$ and $\sigma_{i}$ represent the relative importance of the two issues in the ideology of party $i$. If $\sigma_{i}=\epsilon_{i}$, both issues, nationalism and economic policy, have the same weight on the utility that party $i$ derives from the policy implemented, thus both issues are as important in the ideology of the party. If $\sigma_{i}>\epsilon_{i}$ the position taken on nationalism is regarded as more valuable than the position taken on economic policy by party $i$, and if $\sigma_{i}<\epsilon_{i}$ the position taken on economic policy is regarded as more important than the party's position on nationalism. We have that as the value of $\sigma_{i}$ increases, nationalism becomes more important for party $i$, and therefore party $i$ requires a more favorable compromise on nationalism for a given deal on economic policy. See figure 1. I rule out the possibility that $\sigma_{i}=0$ or $\sigma_{i}=1$ (thus, $\epsilon_{i}=1$ or $\epsilon_{i}=0$ ), since these extreme preferences are rarely observed in the case I analyze: all parties always have cared about both issues.

A necessary condition for a coalition to become a governing coalition is that it has the support of a majority in the parliament. I define a winning coalition as a coalition of parties whose members hold a majority of seats in the parliament.

Within this framework I define an equilibrium outcome as a pair formed by a winning coalition and a policy compromise, such that there is no other winning coalition that could form and offer a policy that would improve the welfare of all its members, that is, I assume that an equilibrium outcome has to satisfy the stand-alone principle.

Definition: An equilibrium outcome is a coalition of parties $C^{*}$, and a policy $\left(e^{*}, s^{*}\right) \in \Re^{2}$ such that:

i) $C^{*}$ is a winning coalition.

ii) There is no $(C,(e, s))$ such that $C$ is a winning coalition and $V_{i}(C,(e, s)) \geq$ $V_{i}\left(C^{*},\left(e^{*}, s^{*}\right)\right)$ for all $i \in C$, with at least one strict inequality.

The assumptions of this model and the definition of equilibrium imply that all the policies that are relevant for my analysis will lie in the Pareto set, that is, the unit square $[0,1]^{2}$. Furthermore, all equilibrium policies will be Pareto Optimal and Individually Rational within the equilibrium coalition.

Given a set of parameter values for each party $\left(k_{i}, v_{i}, \sigma_{i}\right)$ for each $i \in$ $\{P S C+I C, E R C, C I U, P P C\}$, in equilibrium, generically I have a unique equilibrium coalition and a continuum of equilibrium policies. 


\subsection{Acceptable Policy Sets}

The utility that a party obtains from becoming a member of the governing coalition, $k_{i}$, may also be thought of as its reservation value: a party will never accept to become a member of a governing coalition if it has to support a policy from which it derives a (dis)utility larger than the value that the party obtains from holding office.

Formally, the set of policies that party $i$ is willing to accept as government proposals when his alternative is to stay out of office, is given by $A(i)=$ $\left\{(e, s): U_{i}(e, s) \geq 0\right\}$. The size of these sets depend on the value of $k_{i}$ : the larger the value of holding office the larger the set of policies that party $i$ is willing to support in a given governing coalition, that is, the more a party values to be a member of the governing coalition the more flexible it will be in terms of trading-off policy. See figure 2.

A winning coalition that pretends to form a government faces a bargaining problem: the coalition members have to commit to a common policy position. We will say that a policy is acceptable by a certain coalition if there is no other policy that gives a larger utility to one of the parties and no smaller to the others, and gives at least the reservation value to all parties. This implies that an acceptable policy gives all parties in the coalition a utility level of at least their reservation value and it is Pareto Optimal within the coalition's bargaining set. I represent the set of policies that are acceptable by a coalition of two parties $i$ and $j$ by $A(i, j)$. See figure 3 .

Generally, let $A(C)$ denote the set of policies that coalition $C$ is willing to accept as government proposals when the alternative of each member is to stay out of office. Thus, $A(C)=\cap_{i \in C} A(i)$. The size of these sets depend on the value of $k_{i}$ for the members of the coalition: and also on the values of their relative preference intensity.

We need some notation that refers to the boundaries of these sets. Let $\left(e_{i j}^{*}, s_{i j}^{*}\right)$ denote the maximal element in the set $A(j)$ according to party $i$ 's policy preferences, $U_{i}(e, s)$, that is

$$
\left(e_{i j}^{*}, s_{i j}^{*}\right)=\arg \max _{e, s} U_{i}(e, s) \quad \text { s.t. }(e, s) \in A(j)
$$

From the assumptions of my model it is easy to show that this maximal element is unique. Given $\left(e_{i j}^{*}, s_{i j}^{*}\right)$ let's define $u_{i j}^{*}=U_{i}\left(e_{i j}^{*}, s_{i j}^{*}\right)$ that represents the maximal utility level that party $j$ can offer to party $i$.

Finally, given $\left(e_{i j}^{*}, s_{i j}^{*}\right)$ let $\widetilde{e}_{i j}$ and $\widetilde{s}_{i j}$ be defined such that $U_{i}\left(\widetilde{e}_{i j}, s_{i}\right)=$ 
$U_{i}\left(e_{i j}^{*}, s_{i j}^{*}\right)$ and $U_{i}\left(e_{i}, \widetilde{s}_{i j}\right)=U_{i}\left(e_{i j}^{*}, s_{i j}^{*}\right)$ respectively.

In particular, we will have that if parties $i$ and $j$ agree on issue $e$, then $e_{i j}^{*}=e_{i}$ and $\widetilde{s}_{i j}=s_{i j}^{*}$. Similarly, if parties $i$ and $j$ agree on issue $s$, then $s_{i j}^{*}=s_{i}$ and $\widetilde{e}_{i j}=e_{i j}^{*}$.

\subsection{Winning Coalitions}

The assumptions of my model and the definition of equilibrium imply that, generically, equilibrium coalitions must be minimal winning coalitions. A minimal winning coalition is defined as a winning coalition that would not be supported by a majority of seats in the parliament (would not be a winning coalition) if one of its party members was removed from it. The stand-alone principle implies that generically ${ }^{1}$ we will have that only minimal winning coalitions can be part of an equilibrium outcome, as predicted by von Neumann and Morgenstern (1953).

Given the proportion of seats of each party in the parliament, $v_{P S C+I C}$, $v_{E R C}, v_{C I U}$, and $v_{P P C}$, we have only two possible different scenarios in equilibrium:

1) In the "dominant party scenario", there is a party that is a member of all winning coalitions of two parties. We are in this scenario whenever the coalition formed by the largest and the smallest party is a winning coalition.

2) In the "dominated party scenario", there is a party that is not a member of any minimal winning coalition. We are in this scenario whenever the coalition formed by the largest and the smallest party is not a winning coalition.

Furthermore, whenever there is a minimal winning coalition of three parties we are in the dominant party scenario; otherwise, when there is no minimal winning coalition of three parties, we are in the dominated party scenario. This result is stated and proven in Aragones (2007).

In order to illustrate this result consider my four parties and the share of parliament seats that each one controls and suppose that: $v_{C I U} \geq v_{P S C+I C} \geq$ $v_{E R C} \geq v_{P P C}$.

\footnotetext{
${ }^{1}$ Non generically, we can have that a non minimal winning coalition is part of an equilibrium outcome, but in that case there would also be a minimal winning coalition that is part of an equlibrium such that its set of equilibrium policies coincides with the corresponding to first one. Therefore, without loss of generality, we will restrict our equilibrium analysis to minimal winning coalitions.
} 
If $v_{C I U}+v_{P P C}>\frac{1}{2}$ then we are in the dominant party scenario, where the party with the largest number of seats, $C I U$, is the dominant party.

Otherwise, we must have that $v_{C I U}+v_{P P C}<\frac{1}{2}$. In this case we are in the dominated party scenario, where the party with the smallest number of seats, $P P C$, is the dominated party.

Notice that I do not consider the cases in which one party or one coalition holds exactly one half or exactly one quarter of the seats of the parliament. The reason is that in the catalan parliament there are 135 seats, and therefore, those cases can never be observed.

Observe that the dominant party is always the party with the largest number of seats but the party with the largest number of seats is not necessarily the dominant party. Similarly, the dominated party is always the party with the smallest number of seats but the party with the smallest number of seats is not necessarily the dominated party.

\section{Equilibrium Governing Coalitions}

I have shown before that given the distribution of parliament seats among the four parties, there are only two possible scenarios: a dominant party scenario and a dominated party scenario. If we look at the electoral results in the different legislatures of the catalan parliament we find that over time the distribution of seats satisfies the following condition:

$$
v_{C I U}, v_{P S C+I C}>>v_{E R C}, v_{P P C}
$$

This condition is reinforced by the electoral results obtained by these parties in the other elections, such as municipal elections, state elections, european parliament elections, etc... It implies that the possibilities for the catalan parliament are restricted to those cases in which the dominant party is either PSC $+\mathrm{IC}$ or CIU, and those cases in which the dominated party is either ERC or PPC.

In this section, I analyze for each scenario the different governing coalitions that will form in equilibrium and the policy implemented in each case. I assume that for all relevant coalitions the sets of acceptable policies are not empty, whenever it is not stated otherwise. 


\subsection{Dominant Party Scenario}

Suppose that we are in the dominant party scenario and $C I U$ is the dominant party. In this case we have that: $v_{C I U}+v_{E R C}>\frac{1}{2}, v_{C I U}+v_{P S C+I C}>$ $\frac{1}{2}, v_{C I U}+v_{P P C}>\frac{1}{2}$, and $v_{P S C+I C}+v_{E R C}+v_{P P C}>\frac{1}{2}$. The minimal winning coalitions are given by: $C I U$ with $E R C, C I U$ with $P S C+I C, C I U$ with $P P C$, and $P S C+I C$ with $E R C$ and $P P C$.

The relevant strategies in this scenario are the following: party $C I U$ may decide to offer a proposal to form a coalition to any of the other three parties, and each one of the other parties may decide either to accept the proposal from party $C I U$ or to join the three party coalition: $P S C+I C$ with $E R C$ and $P P C$. Thus, there are four possible outcomes in this scenario. I divide the analysis into four different cases that cover all the possibilities. These cases depend on whether the set of acceptable policies for coalition $C I U$ with $P S C+I C$ is empty or not and whether the set of acceptable policies for the three party coalition $(P S C+I C$ with $E R C$ and $P P C)$ is empty or not.

Case 1: $A(C I U, P S C+I C)=\varnothing$ and $A(P S C+I C, E R C, P P C)=\varnothing$

First, suppose that the set of acceptable policies for coalition $C I U$ with $P S C+I C$ is empty, and the set of acceptable policies for the three party coalition is also empty. In this case, the only possibilities for equilibrium are $C I U$ with $E R C$ and $C I U$ with $P P C$. Thus, $C I U$ has to choose his governing partner between $E R C$ and $P P C$. Since neither $E R C$ or $P P C$ can have an alternative feasible offer to form a governing coalition, they can only compete between themselves to become $C I U$ 's partner in the governing coalition.

Since ERC's maximal compromise policy is $\left(e_{C I U, E R C}^{*}, 1\right)$ and PPC's is $\left(1, s_{C I U, P P C}^{*}\right)$, by comparing the utility that $C I U$ derives from each offer we can find out the equilibrium outcome. Since

$$
\begin{aligned}
& U_{C I U}\left(e_{C I U, E R C}^{*}, 1\right)=k_{C I U}-\epsilon_{C I U}\left(1-e_{C I U, E R C}^{*}\right)^{2} \\
& U_{C I U}\left(1, s_{C I U, P P C}^{*}\right)=k_{C I U}-\sigma_{C I U}\left(1-s_{C I U, P P C}^{*}\right)^{2}
\end{aligned}
$$

and $e_{C I U, E R C}^{*}=\sqrt{\frac{k_{E R C}}{\epsilon_{E R C}}}, s_{C I U, P P C}^{*}=\sqrt{\frac{k_{P P C}}{\sigma_{P P C}}}$ and $\epsilon_{C I U}=1-\sigma_{C I U}$, we have that in equilibrium $C I U$ joins $E R C$ in a coalition if and only if

$$
\frac{\sigma_{C I U}}{1-\sigma_{C I U}} \geq \frac{\left(1-\sqrt{\frac{k_{E R C}}{\epsilon_{E R C}}}\right)^{2}}{\left(1-\sqrt{\frac{k_{P P C}}{\sigma_{P P C}}}\right)^{2}}
$$


Similarly, in equilibrium $C I U$ joins $P P C$ in a coalition if and only if

$$
\frac{\sigma_{C I U}}{1-\sigma_{C I U}} \leq \frac{\left(1-\sqrt{\frac{k_{E R C}}{\epsilon_{E R C}}}\right)^{2}}{\left(1-\sqrt{\frac{k_{P P C}}{\sigma_{P P C}}}\right)^{2}}
$$

Thus, $C I U$ joins $E R C$ in an equilibrium coalition when $\sigma_{C I U}$ is large enough, that is, when $C I U$ cares enough about the sovereignty issue. $C I U$ will join $P P C$ in an equilibrium coalition when $\sigma_{C I U}$ is small enough, that is, when $C I U$ cares enough about being rightist. See figures 4 and 5 .

Notice that $U_{C I U}\left(e_{C I U, E R C}^{*}, 1\right) \geq U_{C I U}\left(1, s_{C I U, P P C}^{*}\right)$ if and only if $\widetilde{e}_{C I U, P P C} \leq$ $e_{C I U, E R C}^{*}$ if and only if $\widetilde{s}_{C I U, E R C} \geq s_{C I U, P P C}^{*}$.

In case coalition $C I U$ with $E R C$ forms the equilibrium policies will be those $\left(e^{*}, s^{*}\right)$ such that $e^{*} \in\left(\widetilde{e}_{C I U, P P C}, e_{C I U, E R C}^{*}\right)$ and $s^{*}=1$. Similarly, when coalition $C I U$ with $P P C$ forms the equilibrium policies will be those $(e, s)$ such that $e^{*}=1$ and $s^{*} \in\left(\widetilde{s}_{C I U, E R C}, s_{C I U, P P C}^{*}\right)$.

Case 2: $A(C I U, P S C+I C) \neq \varnothing$ and $A(P S C+I C, E R C, P P C)=\varnothing$.

Suppose that the set of acceptable policies for coalition $C I U$ with $P S C+$ $I C$ is not empty and the set of policies for the three party coalition is empty. In this case, the possibilities for equilibrium coalitions are $C I U$ with $E R C$, $C I U$ with $P S C+I C$, and $C I U$ with $P P C$. Therefore, $C I U$ is clearly the key party, and has to choose among all the other parties its partner in the governing coalition.

The utility that $C I U$ obtains from the best offer of each possible partner is given by:

$$
\begin{aligned}
U_{C I U}\left(e_{C I U, E R C}^{*}, 1\right)= & k_{C I U}-\epsilon_{C I U}\left(1-e_{C I U, E R C}^{*}\right)^{2} \\
U_{C I U}\left(1, s_{C I U, P P C}^{*}\right)= & k_{C I U}-\sigma_{C I U}\left(1-s_{C I U, P P C}^{*}\right)^{2} \\
U_{C I U}\left(e_{C I U, P S C+I C}^{*}, s_{C I U, P S C+I C}^{*}\right)= & k_{C I U}-\epsilon_{C I U}\left(1-e_{C I U, P S C+I C}^{*}\right)^{2} \\
& -\sigma_{C I U}\left(1-s_{C I U, P S C+I C}^{*}\right)^{2}
\end{aligned}
$$

The equilibrium outcome depends on the utility that $C I U$ derives from each policy offer:

i) if $\widetilde{e}_{C I U, P S C+I C} \leq \widetilde{e}_{C I U, P P C} \leq e_{C I U, E R C}^{*}$ and $\widetilde{s}_{C I U, P S C+I C} \leq s_{C I U, P P C}^{*} \leq$ $\widetilde{s}_{C I U, E R C}$

then $C^{*}=(C I U, E R C)$ and $\left(e^{*}, s^{*}\right)$ is such that $e^{*} \in\left(\widetilde{e}_{C I U, P P C}, e_{C I U, E R C}^{*}\right)$ and $s^{*}=1$. 
ii) if $\widetilde{e}_{C I U, P S C+I C} \leq e_{C I U, E R C}^{*} \leq \widetilde{e}_{C I U, P P C}$ and $\widetilde{s}_{C I U, P S C+I C} \leq \widetilde{s}_{C I U, E R C} \leq$ $s_{C I U, P P C}^{*}$

then $C^{*}=(C I U, P P C)$ and $\left(e^{*}, s^{*}\right)$ is such that $e^{*}=1$ and $s^{*} \in$ $\left(\widetilde{s}_{C I U, E R C}, s_{C I U, P P C}^{*}\right)$.

Notice that the analysis of these two sub-cases is exactly like the one performed in case one. Thus, the conditions obtained there also hold here: coalition $C I U$ with $E R C$ forms for large values of $\sigma_{C I U}$ and coalition $C I U$ with $P P C$ forms for small values of $\sigma_{C I U}$.

iii) if $\widetilde{e}_{C I U, P P C} \leq \widetilde{e}_{C I U, P S C+I C} \leq e_{C I U, E R C}^{*}$ and $s_{C I U, P P C}^{*} \leq \widetilde{s}_{C I U, P S C+I C} \leq$ $\widetilde{s}_{C I U, E R C}$

then $C^{*}=(C I U, E R C)$ and $\left(e^{*}, s^{*}\right)$ is such that $e^{*} \in\left(\widetilde{e}_{C I U, P S C+I C}, e_{C I U, E R C}^{*}\right)$ and $s^{*}=1$.

iv) if $e_{C I U, E R C}^{*} \leq \widetilde{e}_{C I U, P S C+I C} \leq \widetilde{e}_{C I U, P P C}$ and $\widetilde{s}_{C I U, E R C} \leq \widetilde{s}_{C I U, P S C+I C} \leq$ $s_{C I U, P P C}^{*}$

then $C^{*}=(C I U, P P C)$ and $\left(e^{*}, s^{*}\right)$ is such that $e^{*}=1$ and $s^{*} \in$ $\left(\widetilde{s}_{C I U, P S C+I C}, s_{C I U, P P C}^{*}\right)$.

The analysis of these two cases is similar to the previous ones, except that here the party that poses a relevant threat to the equilibrium coalition is $P S C+I C$, thus, the policies that can be implemented in equilibrium are determined by PSC+IC's offers. Once more, we obtain as a result that coalition $C I U$ with $E R C$ forms for large values of $\sigma_{C I U}$ and coalition $C I U$ with $P P C$ forms for small values of $\sigma_{C I U}$.

v) if $\widetilde{e}_{C I U, P P C} \leq e_{C I U, E R C}^{*} \leq \widetilde{e}_{C I U, P S C+I C}$ and $s_{C I U, P P C}^{*} \leq \widetilde{s}_{C I U, E R C} \leq$ $\widetilde{s}_{C I U, P S C+I C}$

then $C^{*}=(C I U, P S C+I C)$ and

$\left(e^{*}, s^{*}\right) \in A(C I U, P S C+I C) \cap\left\{(e, s): U_{C I U}(e, s) \geq U_{C I U}\left(e_{C I U, E R C}^{*}, 1\right)\right\}$

vi) if $e_{C I U, E R C}^{*} \leq \widetilde{e}_{C I U, P P C} \leq \widetilde{e}_{C I U, P S C+I C}$ and $\widetilde{s}_{C I U, E R C} \leq s_{C I U, P P C}^{*} \leq$ $\widetilde{s}_{C I U, P S C+I C}$

then $C^{*}=(C I U, P S C+I C)$ and

$\left(e^{*}, s^{*}\right) \in A(C I U, P S C+I C) \cap\left\{(e, s): U_{C I U}(e, s) \geq U_{C I U}\left(1, s_{C I U, P P C}^{*}\right)\right\}$

In these last two cases the party chosen by $C I U$ to form the governing coalition is $P S C+I C$. These cases are not likely to be part of an equilibrium because the offers from $P S C+I C$ may defeat the best offers from CIU's neighbors $(E R C$ and $P P C)$ only under very special conditions. In particular, $C I U$ 's value of holding office must be relatively small and $P S C+I C$ 's value of holding office must be relatively large. See figure 6 .

Case 3: $A(C I U, P S C+I C)=\varnothing$ and $A(P S C+I C, E R C, P P C) \neq \varnothing$ 
Now, suppose that the set of acceptable policies for coalition $C I U$ with $P S C+I C$ is empty and the set of policies for the three party coalition is not empty. In this case, the possibilities for equilibrium coalitions are $C I U$ with $E R C$ and $C I U$ with $P P C$ as before, and in addition we have the three party coalition formed by $P S C+I C$ with $E R C$ and $P P C$.

The different equilibrium outcomes in this case are as follows:

i) if $e_{E R C, C I U}^{*} \leq \widetilde{e}_{E R C, P P C}, s_{P P C, C I U}^{*} \leq \widetilde{s}_{P P C ; E R C}$ and $U_{C I U}\left(\widetilde{e}_{E R C, P P C}, 1\right)>$ $U_{C I U}\left(1, s_{C I U, P P C}^{*}\right)$

then $C^{*}=(C I U, E R C)$ and $\left(e^{*}, s^{*}\right)$ is such that $e^{*} \in\left(\widetilde{e}_{C I U, P P C}, \widetilde{e}_{E R C, P P C}\right)$ and $s^{*}=1$.

ii) if $e_{E R C, C I U}^{*} \leq \widetilde{e}_{E R C, P P C}, s_{P P C, C I U}^{*} \leq \widetilde{s}_{P P C ; E R C}$ and $U_{C I U}\left(\widetilde{e}_{E R C, P P C}, 1\right) \leq$ $U_{C I U}\left(1, s_{C I U, P P C}^{*}\right)$

then there is no equilibrium.

iii) if $e_{E R C, C I U}^{*} \leq \widetilde{e}_{E R C, P P C}, s_{P P C, C I U}^{*} \leq \widetilde{s}_{P P C ; E R C}$ and $U_{C I U}\left(e_{C I U, E R C}^{*}, 1\right)<$ $U_{C I U}\left(1, \widetilde{s}_{P P C, E R C}\right)$

then $C^{*}=(C I U, P P C)$ and $\left(e^{*}, s^{*}\right)$ is such that $e^{*}=1$ and $s^{*} \in$ $\left(\widetilde{s}_{C I U, E R C}, \widetilde{s}_{P P C, E R C}\right)$.

iv) if $e_{E R C, C I U}^{*} \leq \widetilde{e}_{E R C, P P C}, s_{P P C, C I U}^{*} \leq \widetilde{s}_{P P C ; E R C}$ and $U_{C I U}\left(e_{C I U, E R C}^{*}, 1\right) \geq$ $U_{C I U}\left(1, \widetilde{s}_{P P C, E R C}\right)$

then there is no equilibrium.

$\mathrm{v})$ if $e_{E R C, C I U}^{*} \leq \widetilde{e}_{E R C, P P C}$ and $s_{P P C, C I U}^{*} \geq \widetilde{s}_{P P C, E R C}$

then $C^{*}=(C I U, E R C)$ and $\left(e^{*}, s^{*}\right)$ is such that $e^{*} \in\left(e_{E R C, C I U}^{*}, \widetilde{e}_{E R C, P P C}\right)$ and $s^{*}=1$.

vi) if $e_{E R C, C I U}^{*} \geq \widetilde{e}_{E R C, P P C}$ and $s_{P P C, C I U}^{*} \leq \widetilde{s}_{P P C ; E R C}$

then $C^{*}=(C I U, P P C)$ and $\left(e^{*}, s^{*}\right)$ is such that $e^{*}=1$ and $s^{*} \in$ $\left(s_{P P C, C I U}^{*}, \widetilde{s}_{P P C, E R C}\right)$.

The analysis of these cases is similar to the previous ones, and we still have that coalition $C I U$ with $E R C$ forms for large values of $\sigma_{C I U}$ and coalition $C I U$ with PPC forms for small values of $\sigma_{C I U}$.

Consider the following set of policies:

$\widetilde{P}=\left\{(e, s): U_{E R C}(e, s) \geq U_{E R C}\left(e_{E R C, C I U}^{*}, 1\right), U_{P P C}(e, s) \geq U_{P P C}\left(1, s_{P P C, C I U}^{*}\right)\right\}$

vii) if $\widetilde{P} \cap A(E R C, P P C, P S C+I C) \neq \varnothing$ then $C^{*}=(E R C, P P C, P S C+I C)$ and $\left(e^{*}, s^{*}\right) \in \widetilde{P} \cap A(E R C, P P C, P S C+I C)$.

viii) if $e_{E R C, C I U}^{*} \geq \widetilde{e}_{E R C, P P C}, s_{P P C, C I U}^{*} \geq \widetilde{s}_{P P C ; E R C}$ and $\widetilde{P} \cap A(E R C, P P C, P S C+I C)=$ $\varnothing$ then we have no equilibrium.

In Aragones (2007) it is shown that the conditions under which the three party coalition may be part of an equilibrium outcome are very restrictive. It 
is necessary that the reservation values for the three parties in the coalition are large enough in order to guarantee a non empty set of acceptable policies for the three party coalition, and in addition it is necessary that the reservation value of $C I U$ is small enough in order to have it forming in equilibrium. When this is not the case, $C I U$ will play the role of the key party and will choose its partner as before. See figure 7 .

Case 4: $A(C I U, P S C+I C) \neq \varnothing$ and $A(P S C+I C, E R C, P P C) \neq \varnothing$

Suppose that the set of acceptable policies for coalition CIU with $P S C+$ $I C$ is not empty and the set of policies for the three party coalition is not empty. This case is analyzed in detail in Aragones (2007) and it is shown that the coalition between $P S C+I C$ and $C I U$ cannot be part of an equilibrium outcome, because the key party in this case, $C I U$, will always prefer one of the offers from either $E R C$ or $P P C$ to any offer from $P S C+I C$. Thus, the outcomes in this case coincide with the ones found in case 3.

\section{Summary of results for the dominant party scenario:}

I have found that coalition $C I U$ with $P P C$ forms in equilibrium whenever party $C I U$ 's relative preference intensity for nationalism $\left(\sigma_{C I U}\right)$ is small enough. Otherwise, I have shown that coalition $C I U$ with $E R C$ forms in equilibrium whenever party $C I U$ 's relative preference intensity for nationalism $\left(\sigma_{C I U}\right)$ is large enough.

For values of $\sigma_{C I U}$ close to $1 / 2$ we may have different equilibrium outcomes. If the set of acceptable policies by the three party coalition is empty then coalition $C I U$ with $P S C+I C$ may form in equilibrium if $k_{P S C+I C}$ is large enough. If the set of acceptable policies by the three party coalition is not empty then existence of equilibrium is only guaranteed under certain conditions. When they hold we can also have the three party coalition, $P S C+I C$ with $E R C$ and $P P C$ forming in equilibrium. For intermediate values of $\sigma_{C I U}$, coalition $P S C+I C$ with $E R C$ and $P P C$ may form in equilibrium only when $\sigma_{P P C}$ is large enough and $\sigma_{E R C}$ is small enough, $k_{E R C}$ and $k_{P P C}$ are small enough and $u_{C I U}^{*}-k_{C I U}$ is large enough. Otherwise we would have cycles.

Notice that the parameter value that determines which equilibrium prevails in this case is $\sigma_{C I U}$. Observe that the conditions for existence of equilibria with governing coalitions $C I U$ with $P P C$ and $C I U$ with $E R C$ are much weaker that those needed for the equilibria with governing coalition $P S C+I C$ with $E R C$ and $P P C$. Thus, the key party in the 'dominant party scenario' coincides with the dominant party itself, which in this case was $C I U$. 
A parallel analysis would show that the equilibrium outcomes when party $P S C+I C$ is the dominant party can be obtained likewise.

\subsection{Dominated Party Scenario}

Suppose that we are in the dominated party scenario and party $P P C$ is the dominated party. In this case we have that: $v_{P S C+I C}+v_{E R C}>\frac{1}{2}, v_{P S C+I C}+$ $v_{C I U}>\frac{1}{2}$ and $v_{E R C}+v_{C I U}>\frac{1}{2}$. Thus, the minimal winning coalitions are given by: $E R C$ with $P S C+I C, E R C$ with $C I U$, and $P S C+I C$ with $C I U$.

The relevant strategies in this scenario are the following: party $P S C+I C$ may accept to form a coalition with either party $E R C$ or party $C I U$; party $E R C$ may accept to form a coalition with either party $P S C+I C$ or party $C I U$; finally, party $C I U$ may accept to form a coalition with either party $P S C+I C$ or party $E R C$. Thus, there are three possible outcomes in this scenario. I divide the analysis in two different cases that depend on whether the set of acceptable policies for coalition $C I U$ with $P S C+I C$ is empty or not.

Case 1: $A(C I U, P S C+I C)=\varnothing$

Suppose that the set of acceptable policies for coalition $C I U$ with $P S C+$ $I C$ is empty. In this case, the only possibilities for equilibrium coalitions are $E R C$ with $C I U$ and $E R C$ with $P S C+I C$. In this case $E R C$ has to choose his governing partner between $C I U$ and $P S C+I C$. Since neither $C I U$ nor $P S C+I C$ can have an alternative feasible offer to form a governing coalition, they can only compete between themselves to become ERC's partner in the governing coalition.

Since CIU's maximal compromise policy is $\left(e_{E R C, C I U}^{*}, 1\right)$ and $P S C+I C$ 's is $\left(0, s_{E R C, P S C+I C}^{*}\right)$, by comparing the utility that $E R C$ derives from each offer we can find out the equilibrium outcome. Since

$$
\begin{aligned}
U_{E R C}\left(e_{E R C, C I U}^{*}, 1\right) & =k_{E R C}-\epsilon_{E R C}\left(e_{E R C, C I U}^{*}\right)^{2} \\
U_{E R C}\left(0, s_{E R C, P S C+I C}^{*}\right) & =k_{E R C}-\sigma_{E R C}\left(1-s_{E R C, P S C+I C}^{*}\right)^{2}
\end{aligned}
$$

and $e_{E R C, C I U}^{*}=\sqrt{\frac{k_{C I U}}{\epsilon_{C I U}}}, s_{E R C, P S C+I C}^{*}=\sqrt{\frac{k_{P S C+I C}}{\sigma_{P S C+I C}}}$ and $\epsilon_{E R C}=1-\sigma_{E R C}$, we have that in equilibrium $E R C$ joins $C I U$ in a coalition if and only if 


$$
\frac{\sigma_{E R C}}{1-\sigma_{E R C}} \geq \frac{\left(1-\sqrt{\frac{k_{C I U}}{\epsilon_{C I U}}}\right)^{2}}{\left(1-\sqrt{\frac{k_{P S C+I C}}{\sigma_{P S C+I C}}}\right)^{2}}
$$
if

Similarly, in equilibrium $E R C$ joins $P S C+I C$ in a coalition if and only

$$
\frac{\sigma_{E R C}}{1-\sigma_{E R C}} \leq \frac{\left(1-\sqrt{\frac{k_{C I U}}{\epsilon_{C I U}}}\right)^{2}}{\left(1-\sqrt{\frac{k_{P S C+I C}}{\sigma_{P S C+I C}}}\right)^{2}}
$$

Thus, $E R C$ joins $C I U$ in an equilibrium coalition when $\sigma_{E R C}$ is large enough, that is, when $E R C$ cares enough about the sovereignty issue. $E R C$ will join $P S C+I C$ in an equilibrium coalition when $\sigma_{E R C}$ is small enough, that is, when $E R C$ cares enough about being leftist. See figures 8 and 9 .

Notice that $U_{E R C}\left(e_{E R C, C I U}^{*}, 1\right) \geq U_{E R C}\left(0, s_{E R C, P S C+I C}^{*}\right)$ if and only if $e_{E R C, C I U}^{*} \leq \widetilde{e}_{E R C, P S C+I C}$ if and only if $\widetilde{s}_{E R C, C I U} \geq s_{E R C, P S C+I C}^{*}$.

In case coalition $E R C$ with $C I U$ forms the equilibrium policies will be those $\left(e^{*}, s^{*}\right)$ such that $e^{*} \in\left(e_{E R C, C I U}^{*}, \widetilde{e}_{E R C, P S C+I C}\right)$ and $s^{*}=1$. Similarly, when coalition $E R C$ with $P S C+I C$ forms the equilibrium policies will be those $(e, s)$ such that $e^{*}=1$ and $s^{*} \in\left(\widetilde{s}_{E R C, C I U}, s_{E R C, P S C+I C}^{*}\right)$.

Case 2: $A(C I U, P S C+I C) \neq \varnothing$.

Suppose that the set of acceptable policies for coalition $C I U$ with $P S C+$ $I C$ is not empty. In this case, the possibilities for equilibrium coalitions are $E R C$ with $C I U, E R C$ with $P S C+I C$, and $C I U$ with $P S C+I C$.

The equilibrium outcomes in this case are as follows:

i) if $e_{C I U, E R C}^{*} \geq \widetilde{e}_{C I U, P S C+I C}$ and $U_{E R C}\left(\widetilde{e}_{C I U, P S C+I C}, 1\right)>U_{E R C}\left(0, s_{E R C, P S C+I C}^{*}\right)$

then $C^{*}=(E R C, C I U)$ and $\left(e^{*}, s^{*}\right)$ is such that $e^{*} \in\left(\widetilde{e}_{C I U, P S C+I C}, \widetilde{e}_{E R C, P S C+I C}\right)$ and $s^{*}=1$. Notice that in this case it is necessary that $\sigma_{E R C}$ is large enough.

ii) if $e_{C I U, E R C}^{*} \geq \widetilde{e}_{C I U, P S C+I C}$ and $U_{E R C}\left(\widetilde{e}_{C I U, P S C+I C}, 1\right) \leq U_{E R C}\left(0, s_{E R C, P S C+I C}^{*}\right)$ then there is no equilibrium.

iii) if $s_{P S C+I C, E R C}^{*} \leq \widetilde{s}_{P S C+I C, C I U}$ and $U_{E R C}\left(e_{E R C, C I U}^{*}, 1\right)<U_{E R C}\left(0, \widetilde{s}_{P S C+I C, C I U}\right)$ then $C^{*}=(E R C, P S C+I C)$ and $\left(e^{*}, s^{*}\right)$ is such that $e^{*}=1$ and $s^{*} \in$ $\left(\widetilde{s}_{P S C+I C, C I U}, \widetilde{s}_{E R C, C I U}\right)$. Notice that in this case it is necessary that $\sigma_{E R C}$ is small enough.

iv) if $s_{P S C+I C, E R C}^{*} \leq \widetilde{s}_{P S C+I C, C I U}$ and $U_{E R C}\left(e_{E R C, C I U}^{*}, 1\right) \geq U_{E R C}\left(0, \widetilde{s}_{P S C+I C, C I U}\right)$ 
then there is no equilibrium.

Consider the following set of policies:

$\widehat{P}=\left\{(e, s): U_{C I U}(e, s) \geq U_{C I U}\left(e_{C I U, E R C}^{*}, 1\right), U_{P S C+I C}(e, s) \geq U_{P S C+I C}\left(0, s_{P S C+I C, E R C}^{*}\right)\right\}$

v) if $\widehat{P} \neq \varnothing$ then $C^{*}=(C I U, P S C+I C)$ and $\left(e^{*}, s^{*}\right) \in \widehat{P}$. Notice that in this case it is necessary that $k_{E R C}$ is small enough.

vi) if $e_{C I U, E R C}^{*} \leq \widetilde{e}_{C I U, P S C+I C}, s_{P S C+I C, E R C}^{*} \geq \widetilde{s}_{P S C+I C, C I U}$ and $\widehat{P}=\varnothing$

then we have no equilibrium.

The analysis of these cases is similar the one performed for the dominant party scenario. The conditions obtained here are parallel to those found there: coalition $E R C$ with $C I U$ forms for large values of $\sigma_{E R C}$ and coalition $E R C$ with $P S C+I C$ forms for small values of $\sigma_{E R C}$. Only under very special conditions coalition $C I U$ with $P S C+I C$ forms. In particular, $E R C$ 's value of holding must be relatively small and $C I U$ and $P S C+I C$ 's value of holding office must be relatively large. See figures 10 and 11.

\section{Summary of results for the dominated party scenario:}

I have found that coalition $E R C$ with $C I U$ forms in equilibrium whenever party $E R C$ 's relative preference intensity for nationalism $\left(\sigma_{E R C}\right)$ is large enough. Otherwise, I have shown that coalition $E R C$ with $P S C+I C$ forms in equilibrium whenever party $E R C$ 's relative preference intensity for nationalism $\left(\sigma_{E R C}\right)$ is small enough.

For values of $\sigma_{E R C}$ close to $1 / 2$, existence of equilibrium is only guaranteed under certain conditions. When they hold we can have coalition $C I U$ with $P S C+I C$ forming in equilibrium. For intermediate values of $\sigma_{E R C}$, coalition $P S C+I C$ with $C I U$ may form in equilibrium but only when $k_{E R C}$ is small enough and $k_{C I U}$ and $k_{P S C+I C}$ are large enough. Otherwise we would have cycles.

I have shown that the parameter value that determines which equilibrium prevails in this case is $\sigma_{E R C}$. Observe that the conditions for existence of equilibria with governing coalitions $E R C$ with $C I U$ and $E R C$ with $P S C+$ $I C$ are much weaker that those needed for the equilibria with governing coalition $P S C+I C$ with $C I U$. Thus, the key party in the 'dominated party scenario' coincides with the party that opposes completely the dominated party in the ideological space, which in this case is $E R C$, because even if party $E R C$ is not a dominant party it is decisive in almost all cases to determine the composition of the governing coalition.

A parallel analysis would show that the equilibrium outcomes when party $E R C$ is the dominated party can be obtained likewise. 


\section{Discussion of the results}

From the results obtained in the formal model we can explain some determinants of the magnitude of the key party's advantage:

Extreme relative preference intensity: The more extreme the relative preference intensity for one of the two issues, the less likely the existence of the equilibrium in which the key player is left out.

Size of the key party's set of acceptable policies: The larger is the key party's value of holding office, that is, the larger is its set of acceptable policies, the more likely the equilibrium coalition will be the one chosen by the key party.

Size of a coalition's set of acceptable policies: The smaller the set of policies that are acceptable by the coalitions that do not have the key party as a member, the larger the advantage of the key party. As an example of this implication, consider the explicit claim made during the last two legislatures by $E R C$ and $P P C$ that they would not ever be members of the same coalition. This claim can be represented in my model by assuming that the set of acceptable policies by the this coalition is empty, that is, $A(E R C, P P C) \neq \varnothing$. This claim is irrelevant in the dominated party scenario, since in this case the coalitions that involve the dominated party do not play any role (because they are not winning coalitions). However, it has some relevance in the dominant party scenario, since it implies that the three party coalition has an empty set of acceptable policies and this softens the threats that parties can offer to the dominant party, therefore it improves the dominant party's bargain position.

Next I discuss a couple of possible extensions of the formal model:

Vote share and endogenous value of holding office: I have assumed that parties care mostly about holding office, and only instrumentally about policy, and I have represented a party's value of holding office as an exogenous positive constant. Relaxing this assumption, one could think that a party's expected vote in future elections depends positively on the vote support obtained by the party in the current election. Thus I could represent the present value of holding office by an increasing function of the party's current vote share. Suppose that $k_{i}=k\left(v_{i}\right)$ with $k_{i}^{\prime}\left(v_{i}\right) \geq 0$. In this case we will find that the larger the vote share of a party, the larger the utility that it derives from holding office, and the more it would be willing to compromise its policy position in order to become a member of the winning coalition. Thus, the sets of policies that are individually rational will be larger for parties with 
larger vote share. In both the dominant and the dominated party scenarios the size of the vote share of the key player affects the likelihood of existence of the equilibrium in which the key player is left out in a very intuitive way: the larger the vote share of the key party, the less likely it is that the winning coalition that leaves it out can be part of an equilibrium.

Revelation of the parties' preferences: The equilibrium outcomes obtained depend on the parties' values of holding office $\left(k_{i}\right)$ and on their relative intensity of preferences between the two issues $\left(\sigma_{i}\right)$. These values are private information, and it is not obvious that parties will have incentives to reveal their true value. Since the equilibrium outcomes corresponding to a set of parameter values are given by a unique governing coalition and a continuum of policies, it is possible to think of an equilibrium refinement based on the parties' incentives to reveal their private information.

\section{Implications}

The results of my model show that in each possible scenario there is one party that has a clear advantage. I call it the key party. Empirical results from the catalan elections imply that $C I U$ and $P S C+I C$ are the only parties that could play the role of the dominant party, and ERC and PPC are the only ones that could play the role of the dominated party.

When I consider the governments formed in Catalonia between 1980 and 2006, we have that out of the eight different legislatures, six of them are characterized by the dominant party scenario, and only two of them can be represented by the dominated party scenario. We find that PSC $+\mathrm{IC}$ was the dominant party in 1980, CIU has been the dominant party between 1984 and 1999, and PPC has been the dominated party in 2003 and 2006. Furthermore, out of the five legislatures in which CIU has been the dominant party, in three instances CIU has held an absolute majority. See table 3.

In 1980 the governing coalition that formed included CIU, ERC, and UCD, despite PSC+IC was the dominant party. I will not go further into the analysis of the 1980 election because in that election the number of parties that obtained representation in the parliament was much larger than four and the results of our analysis would be much weaker, since I would have to assume that several parties that share the same ideological views over the two dimensions are treated as a unique strategic agent with a common objective. I think that this assumption is too strong and therefore, its results should 
not be considered as significant.

The first three instances in which CIU was a dominant party, CIU had an absolute majority of seats in the parliament, thus, obviously in those cases the government was formed by party CIU alone; there was no need to bargain over policy, and the policy implemented should be interpreted as CIU's ideal point. In the other cases in which CIU was the dominant party (the legislatures starting at 1995 and 1999) a CIU minority government formed with the support of PPC, thus the 'de facto' governing coalition was formed by CIU with PPC. Finally, the governing coalition formed in 2003 and 2006, when PPC was the dominated party, was the three-party coalition that included PSC, IC and ERC.

If we consider possible government coalitions for the future, given the trend of the vote in the past years, we should expect that, as in the past, there will be two parties that will obtain a large share of the seats, and the other two parties will obtain a much smaller share. Thus, it is plausible to expect that also in the future $C I U$ and $P S C+I C$ will be the only parties that could play the role of the dominant party, and $E R C$ and $P P C$ will be the only ones that could play the role of the dominated party.

\section{Strategic Implications}

Given the clear advantage of the key party, it may be in the interest of each party to find out how to increase its chances of becoming the key party. Since the vote share of each party can be though of being determined as an outcome of the electoral campaign, a party's objective during the campaign may imply to obtain a certain composition of the parliament such that the party maximizes his chances of becoming the key party in the formation of the governing coalition. Since $C I U$ and $P S C+I C$ are the only parties that could play the role of the dominant party, they will be interested in obtaining an election result that forces a dominant party scenario in which themselves are the key party. Similarly, since ERC and PPC are the only ones that could play the role of the dominated party, they would prefer an election result that leads to a dominated party scenario in which themselves are the key party.

The results obtained from our analysis imply that compared to the current composition of the parliament and besides increasing their own share of seats, the catalan parties's preferences with respect to the parliament composition 
for the coming elections are as follows:

$C I U$ would like $P P C$ to increase its share of the seats and $P S C+I C$ to decrease its share: $C I U$ would like to maintain a larger proportion of seats than $P S C+I C$ so that increasing $P P C$ 's proportion will take catalan politics back to a dominant party scenario with $C I U$ being the key party.

$P S C+I C$ would like $C I U$ to decrease its share of the seats, and $P P C$ to increase its share, so that $P S C+I C$ could become the key party in a dominant party scenario.

$E R C$ would like $P P C$ not to increase its share, so that the current dominated party scenario continues with $E R C$ being the key party.

$P P C$ would like $E R C$ to decrease its share of seats so that catalan politics moves to a new dominated party scenario with $E R C$ being the dominated party and $P P C$ being the key party.

Considering that the nationalist vote has been held constant over the last elections, if we expect this trend to continue in the future we should expect that the number of parliament seat corresponding to centralist parties equals that corresponding to nationalist parties, that is, $v_{C I U}+v_{E R C} \approx$ $v_{P S C+I C}+v_{P P C}$. This implies that $C I U^{\prime} s$ best option is feasible (increase $C I U$ and $P P C$ 's share and decrease $P S C+I C$ 's share) but $P S C+I C$ best option would not be feasible since it involves increasing both the vote for $P S C+I C$ and the vote for $P P C$.

\section{References}

\section{References}

Aragones, Enriqueta (2007) "Government Formation with a Two Dimensional Policy Space" International Journal of Game Theory, 35 (2): 151-184.

Colomer, Josep M. (1998) "The 'Spanish State of Autonomies': Noninstitutional Federalism" West European Politics, 21(4): 40-52.

Guibernau, Montserrat (1997) "Images of Catalonia" Nations and Nationalism, 3(1): 89-111.

Guibernau, Montserrat (2000) "Spain: Catalonia and the Basque Country" Parliamentary Affairs, 53(1): 55-68. 
Laver, Michael and Norman Schofield (1990). Multiparty Government: The Politics of Coalition in Europe, Oxford University Press.

Moulin, Herve (1988) Axioms of Cooperative Decision Making, Cambridge University Press.

Myerson, Roger (1991) Game Theory. Analysis of Conflict, Harvard University Press.

Plott, Charles (1967) "A Notion of Equilibrium and its Possibility Under Majority Rule" American Economic Review 57: 787-806.

Riker, William (1962) The Theory of Political Coalitions, New Haven: Yale University Press.

Von Neumann, John and Oskar Morgenstern (1953). Theory of Games and Economic Behavior, Princeton University Press.

Weiss, Meredith (2002) "The Catalan Nationalist Movement" case study for project on Globalization and Selfdetermination, Yale Center for International and Area Studies. http://www.yale.edu/ycias/globalization/publications.html 


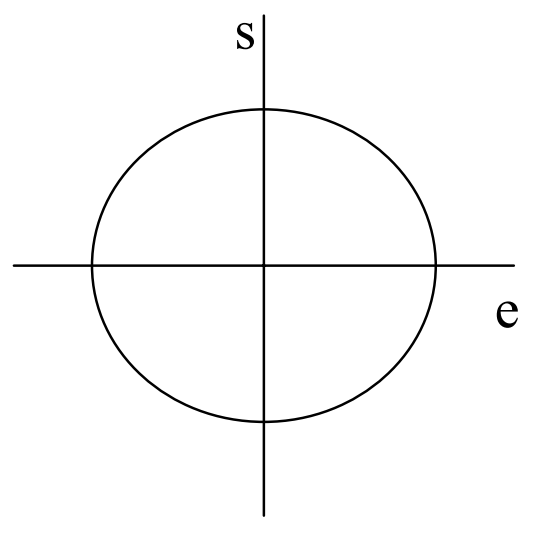

$\varepsilon_{\mathrm{i}}=\sigma_{\mathrm{i}}$

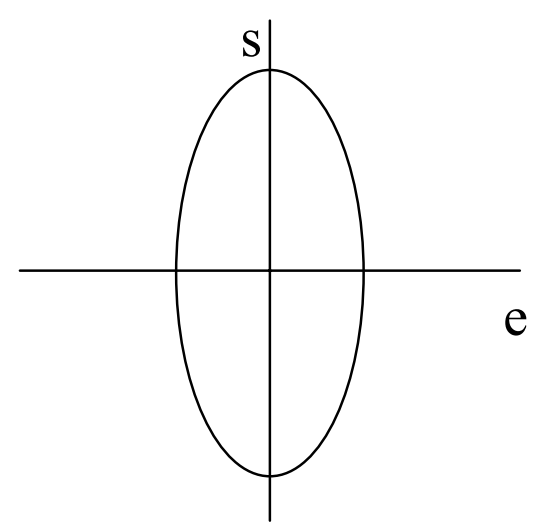

$\varepsilon_{\mathrm{i}}>\sigma_{\mathrm{i}}$

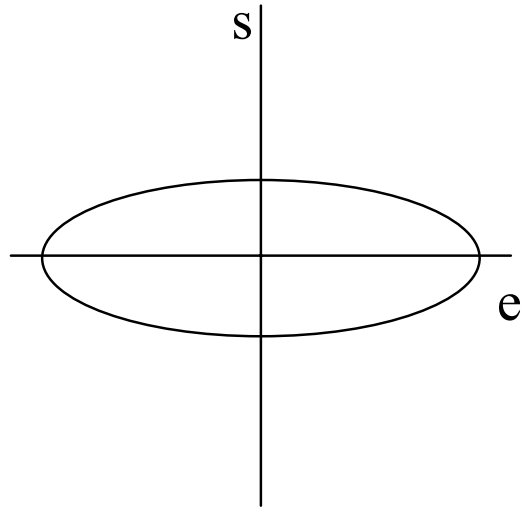

$\varepsilon_{\mathrm{i}}<\sigma_{\mathrm{i}}$

FIGURE 1: Indifference curves.

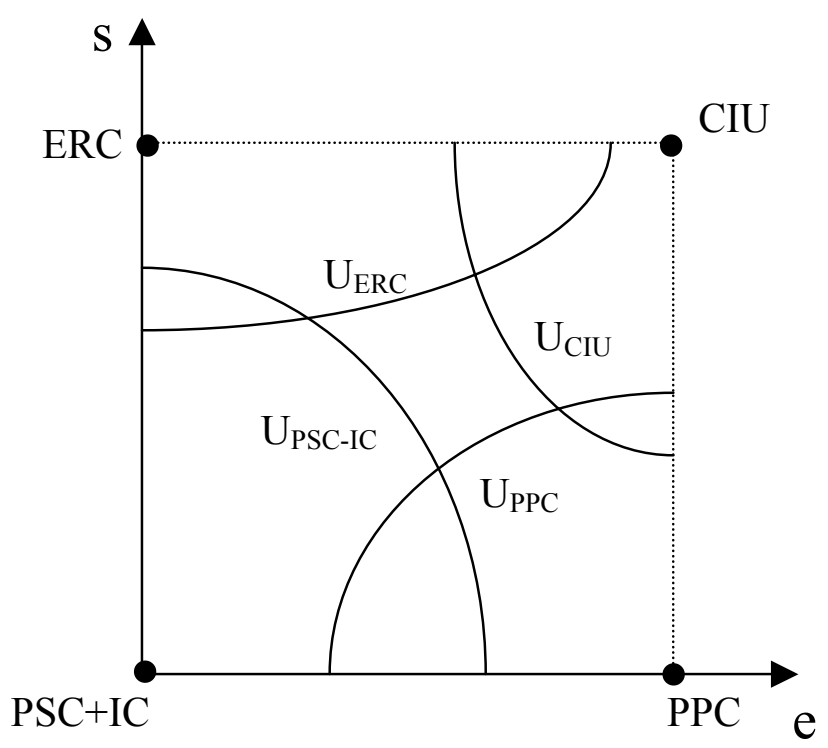

FIGURE 2: Acceptable set of policies for each party. 


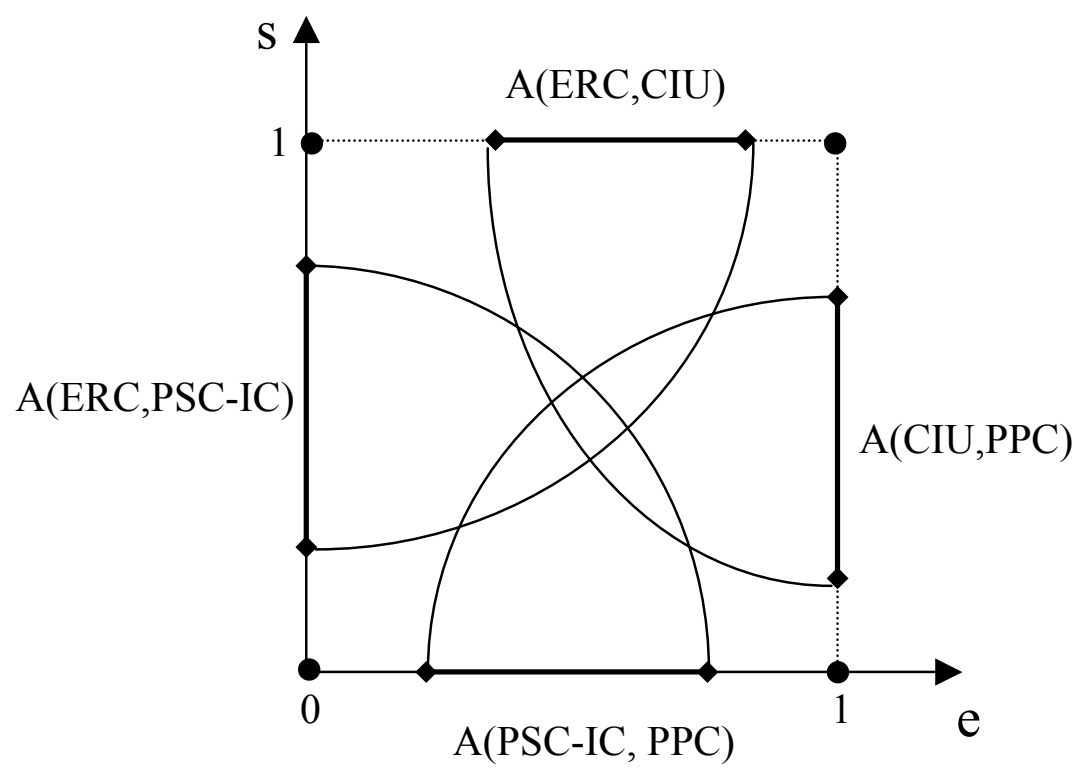

FIGURE 3: Policies acceptable by coalitions of 2 parties that agree on one issue.

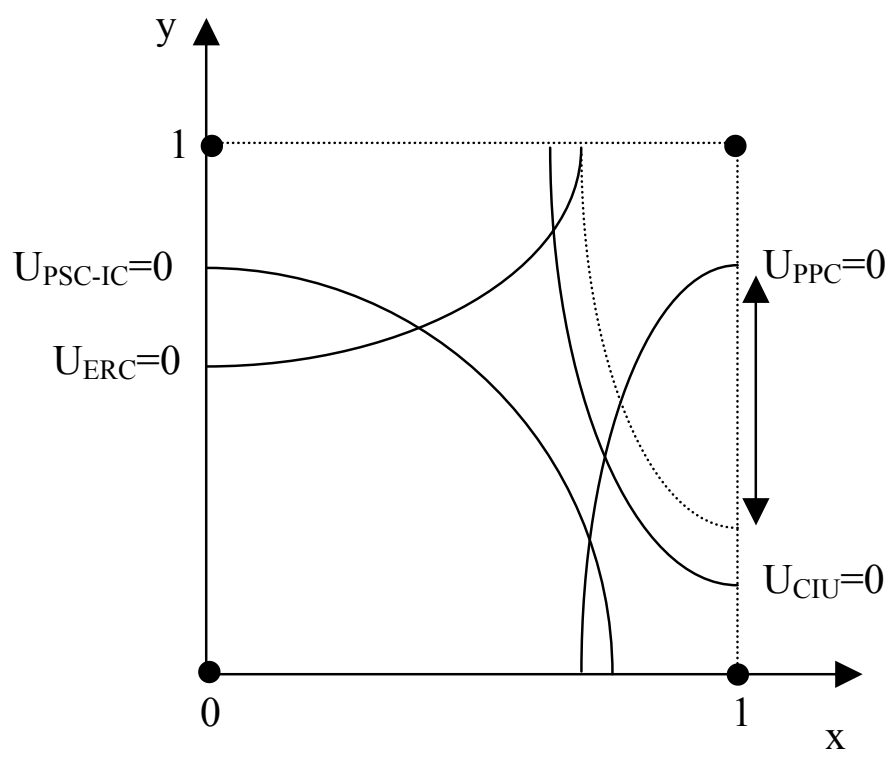

FIGURE 4: CIU dominant, A(CIU,PSC$\mathrm{IC})=\varnothing, \mathrm{A}(\mathrm{PSC}-\mathrm{IC}, \mathrm{ERC}, \mathrm{PPC})=\varnothing$ and $\sigma_{\mathrm{CIU}}$ small.

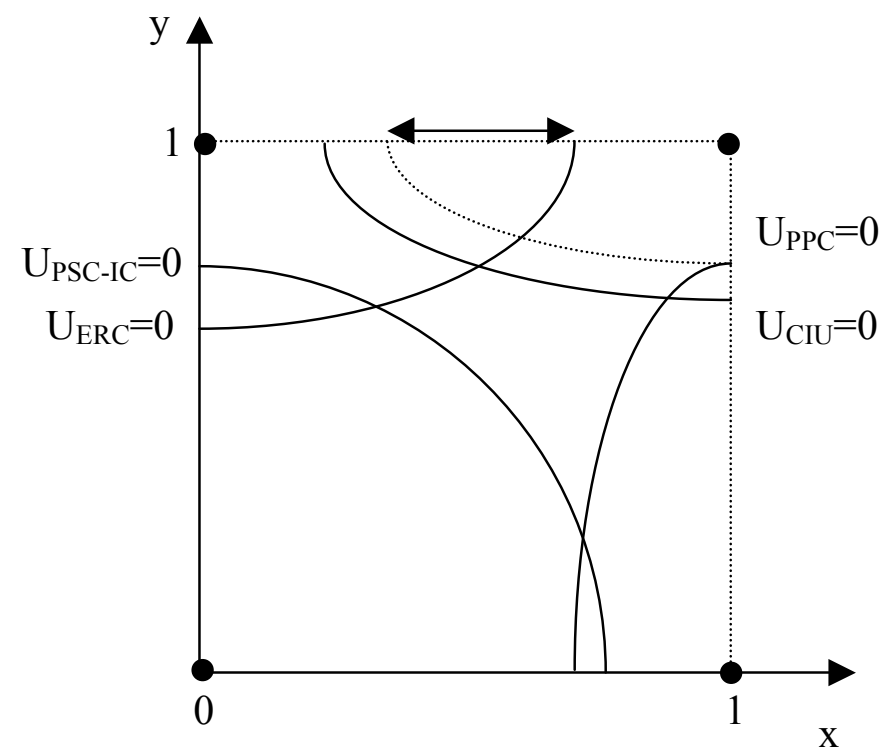

FIGURE 5: CIU dominant, A(CIU,PSC$\mathrm{IC})=\varnothing, \mathrm{A}(\mathrm{PSC}-\mathrm{IC}, \mathrm{ERC}, \mathrm{PPC})=\varnothing$ and $\sigma_{\mathrm{CIU}}$ large. 


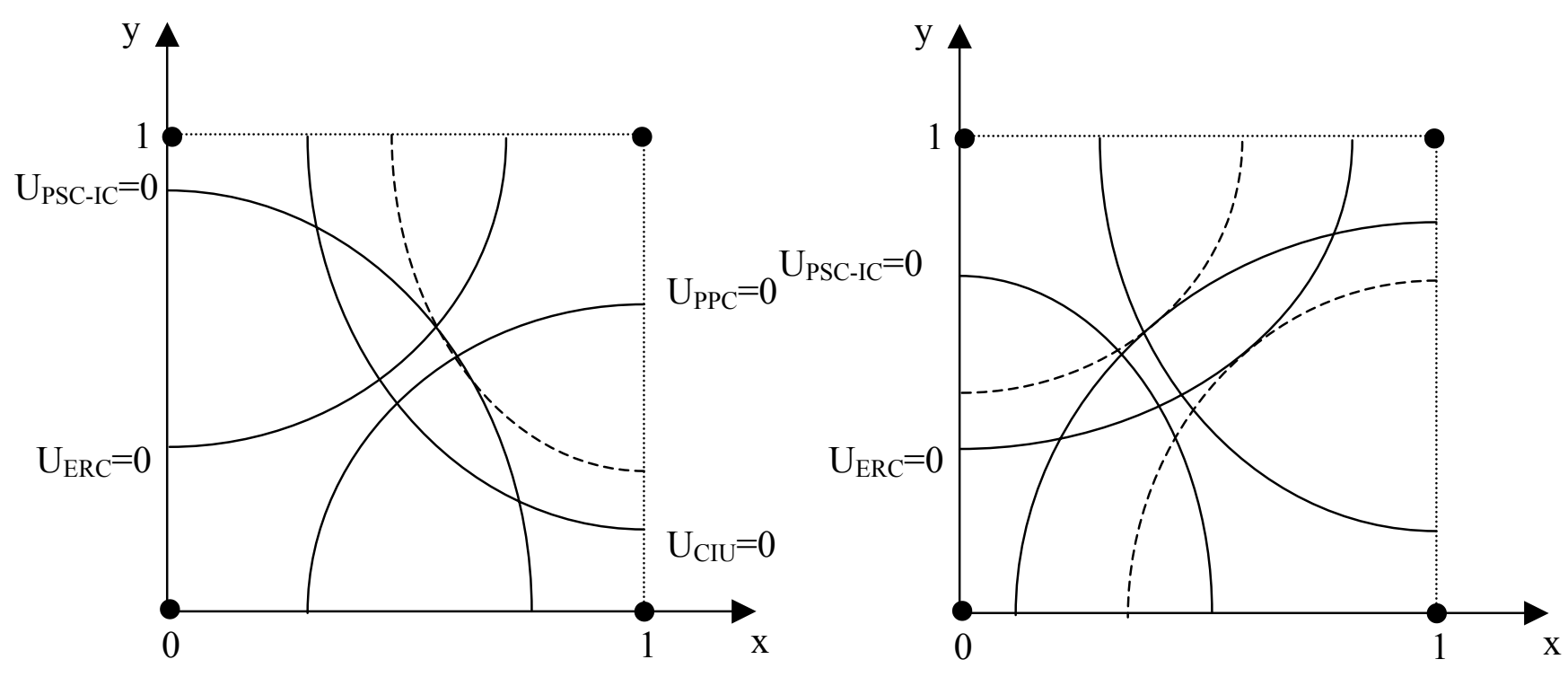

FIGURE 6: CIU dominant, $\mathrm{A}(\mathrm{CIU}, \mathrm{PSC}-\mathrm{IC}) \neq \varnothing$ and $\mathrm{A}$ (PSC$\mathrm{IC}, \mathrm{ERC}, \mathrm{PPC})=\varnothing$.

FIGURE 7: CIU dominant and $\mathrm{A}(\mathrm{PSC}-\mathrm{IC}, \mathrm{ERC}, \mathrm{PPC}) \neq \varnothing$.

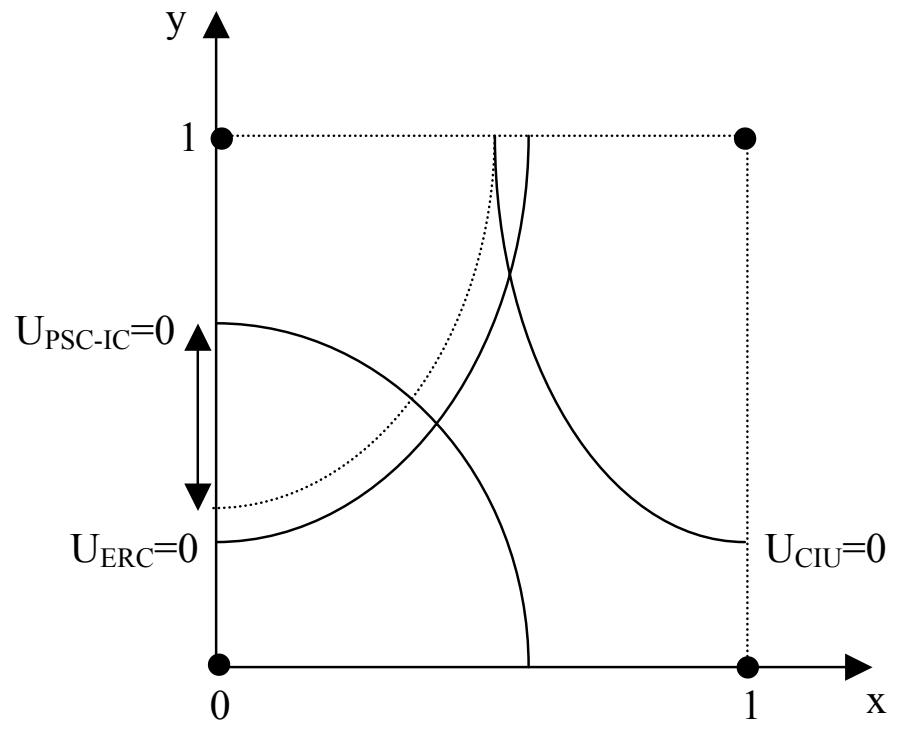

FIGURE 8: PPC dominated, $\mathrm{A}(\mathrm{CIU}, \mathrm{PSC})=\varnothing$ and $\sigma_{\mathrm{ERC}}$ small.

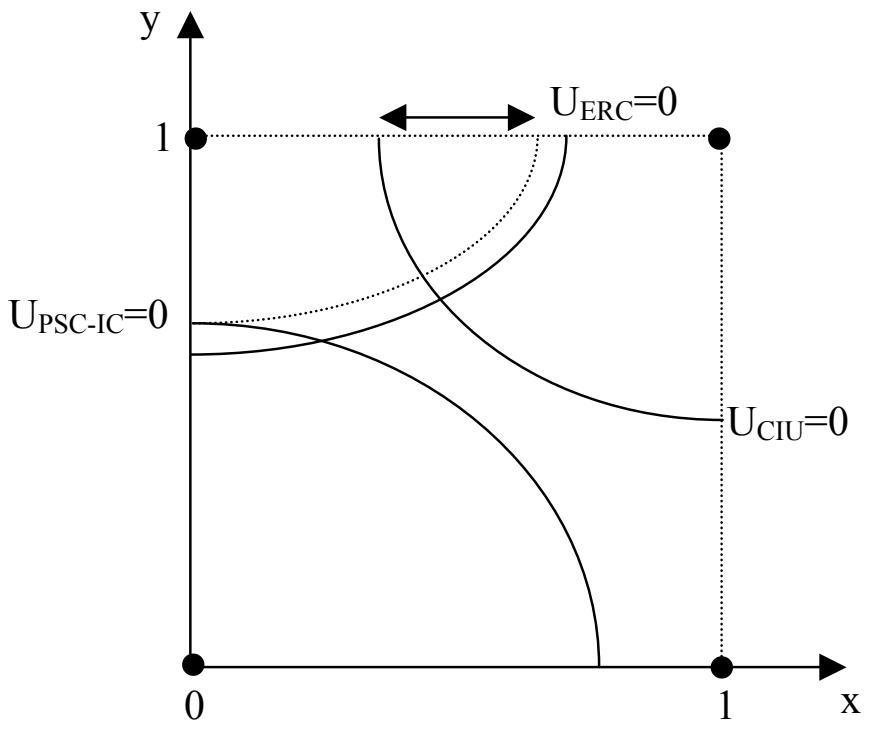

FIGURE 9: PPC dominated, $\mathrm{A}(\mathrm{CIU}, \mathrm{PSC}-\mathrm{IC})=\varnothing$ and $\sigma_{\mathrm{ERC}}$ large. 


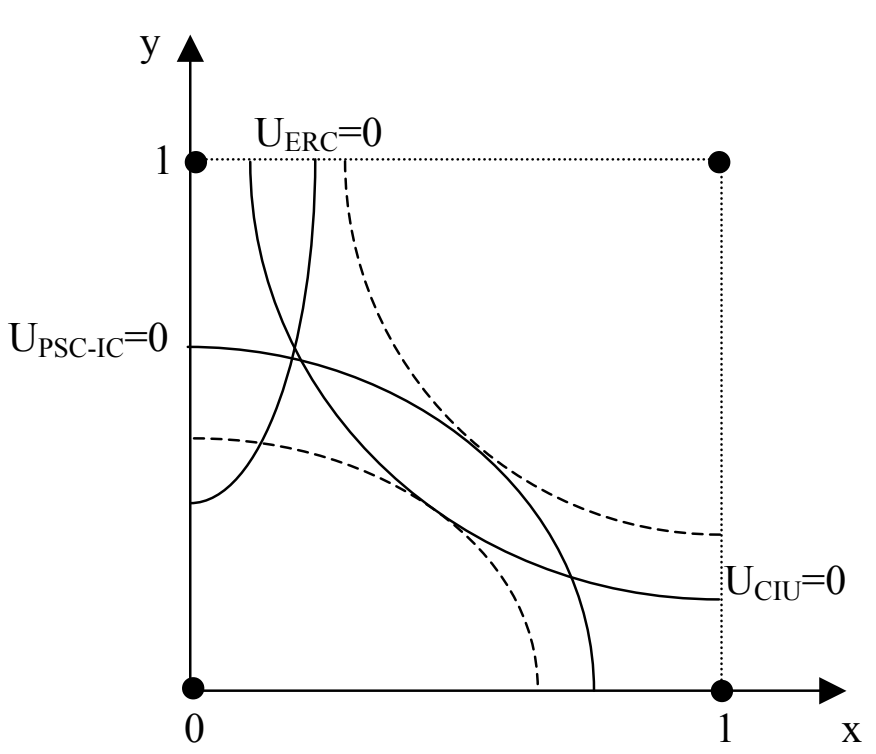

FIGURE 10: PPC dominated, $\mathrm{A}(\mathrm{CIU}, \mathrm{PSC}-\mathrm{IC}) \neq \varnothing$ and $\sigma_{\mathrm{ERC}}$ small.

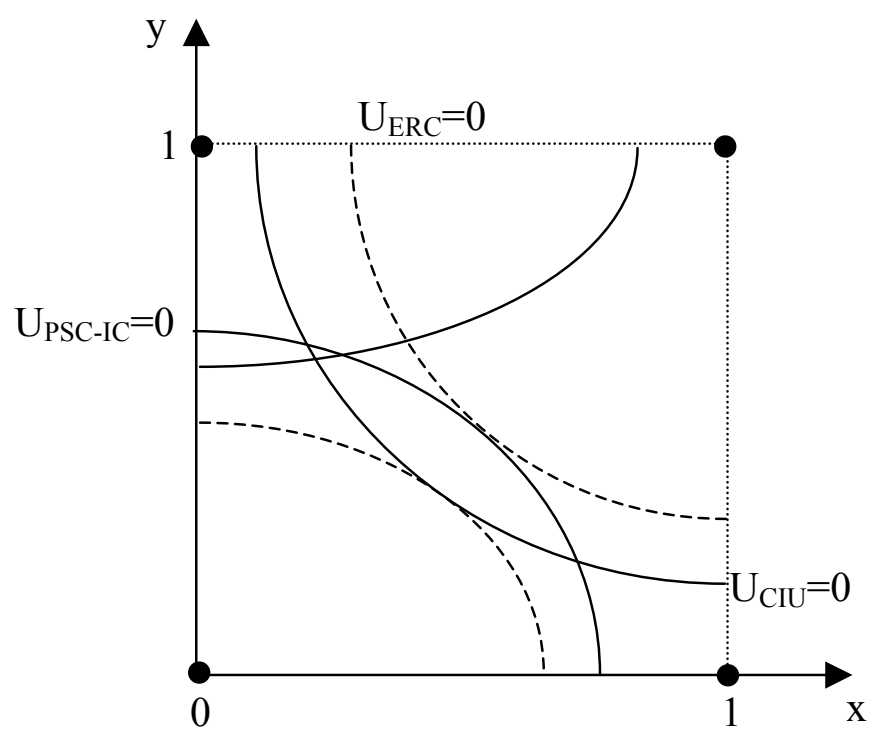

FIGURE 11: PPC dominated, $\mathrm{A}(\mathrm{CIU}, \mathrm{PSC}-\mathrm{IC}) \neq \varnothing$ and $\sigma_{\text {ERC }}$ large. 


\begin{tabular}{ccccccccc}
\hline & 80 & 84 & 88 & 92 & 95 & 99 & 03 & 06 \\
\hline CIU & 43 & 72 & 69 & $\mathbf{7 0}$ & $\mathbf{6 0}$ & $\mathbf{5 6}$ & $\mathbf{4 6}$ & $\mathbf{4 8}$ \\
ERC & 14 & 5 & 6 & 11 & 13 & 12 & 23 & 21 \\
AP & - & 11 & 6 & - & - & - & - & - \\
PPC & - & - & - & 7 & 17 & 12 & 15 & 14 \\
UCD & 18 & - & - & - & - & - & - & - \\
CDS & - & - & 3 & - & - & - & - & - \\
C & - & - & - & - & - & - & - & 3 \\
PSC & 33 & 41 & 42 & 40 & 34 & 52 & 42 & 37 \\
PSUC & 25 & 6 & - & - & - & - & - & - \\
PSA & 2 & - & - & - & - & - & - & - \\
IC-EV & - & - & 9 & 7 & $\mathbf{1 1}$ & $\mathbf{3}$ & 9 & 12 \\
\hline
\end{tabular}

Table 1: Distribution of seats among parties in the Catalan Parliament.

\begin{tabular}{ccccccccc}
\hline & $\mathbf{8 0}$ & $\mathbf{8 4}$ & $\mathbf{8 8}$ & $\mathbf{9 2}$ & $\mathbf{9 5}$ & $\mathbf{9 9}$ & $\mathbf{0 3}$ & $\mathbf{0 6}$ \\
\hline CIU & $\mathbf{4 3}$ & $\mathbf{7 2}$ & $\mathbf{6 9}$ & $\mathbf{7 0}$ & $\mathbf{6 0}$ & $\mathbf{5 6}$ & $\mathbf{4 6}$ & $\mathbf{4 8}$ \\
ERC & 14 & 5 & 6 & 11 & 13 & $\mathbf{1 2}$ & 23 & 21 \\
PPC & $\mathbf{1 8}$ & 11 & 9 & 7 & 17 & 12 & $\mathbf{1 5}$ & $\mathbf{1 7}$ \\
PSC+IC & $\mathbf{6 0}$ & $\mathbf{4 7}$ & $\mathbf{5 1}$ & $\mathbf{4 7}$ & $\mathbf{4 5}$ & $\mathbf{5 5}$ & $\mathbf{5 1}$ & $\mathbf{4 9}$ \\
\hline
\end{tabular}

Table 2: Distribution of seats among ideological groups in the Catalan Parliament.

\begin{tabular}{ccccccccc}
\hline & 80 & 84 & 88 & 92 & 95 & 99 & 03 & 06 \\
\hline CIU & $31.8 *$ & $53.3 *$ & $51.1 *$ & $51.8 *$ & $44.4 *$ & $41.5 *$ & 34.1 & 35.5 \\
ERC & 10.4 & 3.7 & 4.4 & 8.1 & 9.6 & 8.9 & $17.0 *$ & $15.5 *$ \\
PPC & 13.3 & 8.1 & 6.7 & 5.1 & 12.6 & 8.9 & 11.1 & 12.6 \\
PSC+IC & 44.4 & 34.8 & 37.8 & 34.8 & 33.3 & 40.7 & 37.8 & 36.3 \\
\hline
\end{tabular}

Table 3: Percentage of seats corresponding to each ideological group. 